\title{
Valores Energéticos do Milheto, do Milho e Subprodutos do Milho, Determinados com Frangos de Corte e Galos Adultos ${ }^{1}$
}

\author{
Paulo Borges Rodrigues ${ }^{2}$, Horacio Santiago Rostagno ${ }^{3}$, Luiz Fernando Teixeira Albino ${ }^{3}$, \\ Paulo Cezar Gomes ${ }^{3}$, Walter Amaral Barboza4, Rodrigo Toledo Santana ${ }^{5}$
}

RESUMO - Dois experimentos foram conduzidos para determinar os valores de energia metabolizável aparente(EMA) e verdadeira(EMV) de 11 alimentos (amostras de milho e seus subprodutos e de milheto), utilizando o método tradicional de coleta total de excretas, com pintos em crescimento e o método da alimentação forçada, com galos adultos (método Sibbald). No exp. I, 540 pintos Hubbard machos receberam as rações experimentais em quatro repetições de 10 aves cada, exceto a ração referência, a qual foi fornecida a seis repetições. No exp. II, cada um dos 11 alimentos foram fornecidos a 6 galos, os quais receberam $15 \mathrm{~g}$ do alimento pela manhã $(8 \mathrm{~h})$ e $15 \mathrm{~g}$ à tarde ( $16 \mathrm{~h})$, após terem sofrido um período de jejum de 24 horas. Simultaneamente, seis galos foram mantidos em jejum, para determinação das perdas endógenas e metabólicas. Após determinados os valores de EMAn com pintos e EMVn com galos, estabeleceram-se equações para predizer os valores energéticos dos alimentos do grupo do milho e seus subprodutos, em função de sua composição química. As EMAn e EMVn dos alimentos testados variaram de 1937 a 4108 e de 2246 a 4248 kcal/kg de matéria seca, respectivamente. Os resultados mostraram que o milheto poderá constituir-se em um alimento alternativo ao milho, porém com valores energéticos pouco inferiores ao milho. As equações de predição ajustadas com as variáveis fibra em detergente neutro (FDN) ou fibra bruta (FB) e matéria mineral (MM) podem ser utilizadas para predizer os valores energéticos do milho e de seus subprodutos, sendo EMAn $=4281,6-39,97 \mathrm{FDN}-72,90 \mathrm{MM}\left(\mathrm{R}^{2}=0,96\right)$ ou $\mathrm{EMAn}=4354,8-112,05 \mathrm{FB}-151,74 \mathrm{MM}\left(\mathrm{R}^{2}\right.$ $=0,95)$ e $E M V n=4485,1-34,20 F D N-83,83 M M\left(R^{2}=0,94\right)$ ou $E M V n=4250,22-136,60 F B-120,48 M M\left(R^{2}=0,91\right)$.

Palavras-chave: frangos de corte, galos, energia metabolizável, equações de predição, milho, milheto

\section{Energy Values of Millet, Corn and Corn Byproducts, Determined with Broilers and Adult Cockerels}

\begin{abstract}
S - Two metabolism assays were carried out in order to evaluate the aparent metabolizable energy (AME) and true metabolizable energy (TME) values of 11 feedstuffs (corn and corn byproducts and of the millet samples) by using the traditional method of excreta collection with growing chickens and the forced feeding method, by using adult cockerels (Sibbald method). In the first assay, 540 male Hubbard chickens fed the experimental diets in four replicates with ten birds in each experimental unit and the basal diet fed to six replicates. In the second assay, each one of 11 feedstuffs was fed to six cockerels, $15 \mathrm{~g}$ were fed at 8:00 a.m. and 15 g were fed at 4:00 p.m., after fastening by 24 hours. Simultaneously six cockerels were fasted in order to determine the metabolic and endogenous nitrogen losses. After determination of AMEn and TMEn values, prediction equations were simulated to predict the energetic values of the corn and corn byproducts, based on chemical composition. The AMEn and TMEn of feed evaluated ranged from 1937 to 4108 and from 2246 to $4248 \mathrm{kcal} / \mathrm{kg}$ of dry matter, respectively. The results shown that millet should be one alternative feed to corn, with lower energetic value. The prediction equations adjusted with the variables neutral detergent fiber (NDF) or crude fiber (CF) and ash should be used to predict the energetic values of corn and corn byproducts, being AMEn $=4281.6-39.97-72.90 \mathrm{ash}\left(\mathrm{R}^{2}=0.96\right)$ or EMAn $=4354.8-112.05 \mathrm{CF}$ $-151.74 \mathrm{ash}\left(\mathrm{R}^{2}=0.95\right)$ and $\mathrm{EMVn}=4485.1-34.20 \mathrm{NDF}-83.83 \mathrm{ash}\left(\mathrm{R}^{2}=0.94\right)$ or $4250.22-136.60 \mathrm{CF}-120.48 \mathrm{ash}\left(\mathrm{R}^{2}=0.91\right)$.
\end{abstract}

Key Words: broiler chickens, cockerels, metabolizable energy, prediction equations, corn, millet

\section{Introdução}

A maximização do potencial de desenvolvimento animal depende de vários fatores. Ao lado de condições favoráveis, inerentes ao ambiente de criação e da saúde dos animais, a nutrição correta, adotando-se técnicas aprimoradas no preparo das rações, consti- tuem-se em pressupostos básicos para a otimização da produção (ZANOTTO e MONTICELLI, 1998). Assim, a alimentação animal representa um fator importante na agroindústria brasileira e, no ano de 1999, o setor avícola foi responsável por uma demanda em torno de 12 milhões e 500 mil toneladas de milho, acreditando-se que, no ano de 2000 este valor supe-

\footnotetext{
${ }_{1}^{1}$ Parte da tese de Doutorado do primeiro autor. Projeto financiado pelo CNPq.

2 Professor do Departamento de Zootecnia da UFLA. E.mail: pborges@ufla.br

3 Professores do Departamento de Zootecnia da UFV. E.mail: rostagno@mail.ufv.br

${ }^{4}$ Professor do Departamento de Zootecnia da UFRPE.

${ }^{5}$ Aluno do curso de Mestrado do Departamento de Zootecnia da UFV.
} 
rasse 13 milhões de toneladas (ANFAL, 2000). Apesar da constante busca de alimentos alternativos, observa-se que o milho é ainda a fonte energética tradicional nas formulações.

Por outro lado, a literatura tem mostrado que o milheto, pelo alto teor de proteína bruta dos grãos, bem como pela sua composição energética e mineral, pode ser um cereal alternativo em substituição ao milho nas formulações, o que tem despertado grande interesse dos nutricionistas nos últimos anos (ALBINO et al., 1992b; CAFÉ et al., 1996; COLLINS et al., 1997; RAGLAND et al., 1997). Portanto, é imprescindível o conhecimento de seu valor nutritivo para aves.

Segundo ALBINO et al. (1987), a grande variação existente entre solos e clima afeta a composição química dos alimentos e, conseqüentemente, sua energia, o mesmo ocorrendo com os subprodutos industriais, em função do processamento adotado. Dessa forma, o conhecimento da composição química e precisão dos valores energéticos dos alimentos são de grande importância na formulação econômica de rações. Vários métodos diretos (ensaios biológicos) e indiretos (equações de predição) têm sido aplicados na determinação da energia metabolizável dos alimentos para aves. Diante de tais colocações, os objetivos do presente trabalho foram determinar os valores energéticos (EMA, EMAn, EMV e EMVn) do milheto, do milho e subprodutos, por intermédio de um ensaio com pintos em crescimento (método tradicional) e outro utilizando galos adultos (alimentação forçada), e estabelecer equações por meio dos resultados experimentais obtidos e da composição química, para predizer o conteúdo energético do milho e subprodutos.

\section{Material e Métodos}

Em dois experimentos foram determinados os valores de energia metabolizável aparente (EMA), aparente corrigida (EMAn), verdadeira (EMV) e verdadeira corrigida (EMVn) de onze alimentos obtidos de empresas comerciais, sendo três amostras de milho (milhos 1, 2 e QPM - Quality Protein Maize), milho pré-cozido, farelo de glúten 60 , farelo de glúten 21 , gérmen de milho, gérmen de milho fino, gérmen de milho desengordurado e duas amostras de milheto (milhetos 1 e 2). O milho QPM representa uma variedade de milho originalmente desenvolvida pelo Centro Internacional de Melhoramento de Milho e
Trigo, no México, melhorada em suas qualidades agronômicas e de composição em aminoácidos pelo Centro Nacional de Pesquisas em Milho e Sorgo (CNPMS - EMBRAPA) de Sete Lagoas/Minas Gerais. A variedade foi melhorada para conter $50 \%$ a mais de lisina, em relação ao milho comum. O milho pré-cozido é o produto obtido do grão de milho moído, extrusado a vapor (pré-cozimento a $85-90^{\circ} \mathrm{C}$ ), passando posteriormente por um processo de secagem, novamente moído e destinado à alimentação animal (SIMILHO Indústria e Comércio de Milho Guimarães LTDA - Uberlândia/Minas Gerais).

Os experimentos foram conduzidos no Laboratório Animal do Departamento de Zootecnia (DZO) da Universidade Federal de Viçosa (UFV). O experimento 1 foi conduzido com pintos em crescimento, dos 22 aos 26 dias de idade (método tradicional de coleta total de excretas) e o experimento 2 com galos adultos (alimentação forçada).

No experimento 1 foram utilizados 540 pintos machos da linhagem Hubbard, criados em galpão de alvenaria no Setor de Avicultura do DZO, até a idade de 14 dias, período no qual receberam uma ração inicial de frangos de corte baseada em milho e farelo de soja, apresentando peso médio de 348,1 $\pm 1,8 \mathrm{~g}$ aos 14 dias. As aves foram então transferidas para baterias metálicas e distribuídas aleatoriamente aos boxes das baterias, onde receberam as rações com os alimentos a serem testados e luz natural e, ou, artificial por 24 horas. Os 11 alimentos testados foram adicionados em uma ração referência (Tabela 1), na proporção de $40 \%$, com exceção do farelo de glúten 60 , que, pelo seu elevado conteúdo de PB, substituiu a ração referência em 30\%. Determinaram-se, para cada alimento, as EMA, EMAn, EMV e EMVn em quatro repetições de dez aves cada, sendo a ração referência fornecida a seis repetições de dez aves, por ser fundamental nos cálculos dos valores energéticos. Rações e água foram fornecidas à vontade por um período de 12 dias, sendo sete dias de adaptação e cinco de coleta total de excretas em cada unidade experimental, a qual foi realizada duas vezes ao dia ( 8 e 16 h) para evitar fermentações. Simultaneamente, foram mantidas em jejum quatro repetições de dez aves, por um período de 24 horas, para limpar o trato digestivo e por mais 48 horas, para determinação das perdas endógenas e metabólicas, cujos valores foram corrigidos para o período de cinco dias, equivalente ao período de coleta de excretas, para se determinarem as EMV e EMVn. 
Tabela 1 - Composição centesimal e calculada da ração referência

Table 1 - Calculated and centesimal composition of the reference diet

Ingredientes

$(\%)$

Ingredients

Milho

63,240

Corn

Farelo de soja

28,545

Soybean meal

Farinha de carne e ossos

3,000

Meat and bone meal

Gordura de aves

2,500

Poultryfat

Fosfato bicálcico

0,700

Dicalcium phosphate

Calcário

Limestone

Sal

Salt

DL-Metionina

DL-Methionine

L-Lisina HCL

L-Lysine $\mathrm{HCl}$

Premix vitamínico ${ }^{1}$

Vitaminic premix

Premix mineral $^{2}$

Mineral premix

Cloreto de colina

Choline chloride

Anticoccidiano $^{3}$

Anticoccidian

Promotor de crescimento 4

Growth promoter

Inerte

Inert

Antioxidante 5

Antioxidant

Total

Composição calculada

Calculated composition

Energia metabolizável (kcal $/ \mathrm{kg}$ )

Metabolizable energy ( $\mathrm{kcal} / \mathrm{kg}$ )

Proteína bruta

Crude protein

Metionina + cistina

Methionine + cystine

Lisina

Lysine

Cálcio

Calcium

Fósforo disponível

Available phosphorus

Sódio

Sodium

${ }^{1}$ Contendo porkg (Contents by kg): Vit. A-15.000.000 Ul; Vit. $D_{3}-1.500 .000$ Ul; Vit E - 15.000 Ul; Vit $B_{1}-2,0$ g; Vit $B_{2}-4,0$ g; Vit $B_{6}-3,0$ g; Vit $B_{12}-$ 0,015 g; Ácido nicotínico (Nicotinic acid) - 25,0 g; Ác. Pantotênico (Pantotenic acid) - 10,0 g; Vit. $\mathrm{K}_{3}-3,0 \mathrm{~g}$; Ác. fólico (Folic acid) $-1,0 \mathrm{~g}$; Bacitracina de zinco (Zinc bacitracin) - 10,0 g; Selênio (Selenium) - 0,25 g; antioxidante (antioxidant) - 10,0 g e veículo q.s.p. - $1000 \mathrm{~g}$.

2 Contendo por Kg (Contents by Kg): Manganês (Manganese) - 80 g; Ferro (Iron) - 80 g; Zinco (Zinc) - 50 g; Cobre (Copper) - $10 \mathrm{~g}$; Cobalto (Cobalt)

- $2 \mathrm{~g}$; lodo (lodine) - $1 \mathrm{~g}$ e veículo q.s.p. - $500 \mathrm{~g}$.

3 Monensina sódica $20 \%$ (Sodic monensin 20\%).

${ }^{4}$ Virginiamicina $2 \%$ (Virginiamicin 2\%).

5 Butil Hidroxi Tolueno 99\% (Butil Hidroxi Toluen 99\%).
O consumo de ração de cada unidade experimental, durante o período de coleta, foi registrado e as excretas coletadas, colocadas em sacos plásticos devidamente identificados e armazenadas em freezer até o final do período de coleta. Então, as amostras foram pesadas, homogeneizadas e retiradas as alíquotas devidas para as análises de MS, $\mathrm{N}$ e EB, após pré-secagem em estufa ventilada a $55^{\circ} \mathrm{C}$ por um período de 72 horas. Os valores de EMA foram determinados pela fórmula de MATTERSON et al. (1965) e ajustados para a retenção de nitrogênio e a repetibilidade média, conforme fórmula citada por ALBINO (1991).

A composição química dos alimentos foi determinada conforme as técnicas descritas por SILVA (1990). O amido, determinado pelo método colorimétrico de Somogy-Nelson, descrito por NELSON (1944), e o selênio (Se) por intermédio da metodologia descrita por AMERLIN et al. (1998). Também foram realizadas análises físicas para determinar o diâmetro geométrico médio - DGM (adaptado da metodologia de Zanotto e Bellaver, 1996, citados por ZANOTTO e MONTICELLI, 1998) e a densidade dos alimentos.

No segundo experimento foi utilizado o método de alimentação forçada (SIBBALD, 1976), utilizando-se galos Legorne adultos, com 18 meses de idade e peso médio de $2352 \pm 205 \mathrm{~g}$. Cada um dos 11 alimentos descritos no experimento 1 foi fornecido a seis galos, repetidos três vezes no tempo, sendo dois galos por unidade experimental. Simultaneamente, foram mantidas em jejum três repetições de dois galos, para determinação das perdas endógenas. Foi utilizado um intervalo de quatro dias entre cada repetição, para descanso dos galos, os quais receberam uma ração de terminação de frangos de corte, visando melhor recuperação. Antes do período experimental, os galos foram alojados nas baterias e passaram por um período de adaptação, no qual receberam alimentação em dois turnos de 1 hora, às 8 e $16 \mathrm{~h}$, visando a dilatação do papo. Em seguida, foram mantidos em jejum por 24 horas, com o objetivo de esvaziar o trato digestivo, e, então, forçados a ingerir $30 \mathrm{~g}$ do alimento teste, por meio de um funil-sonda introduzido via esôfago até o papo. Foram fornecidos $15 \mathrm{~g}$ dos alimentos às $8 \mathrm{~h}$ e $15 \mathrm{~g}$ às $16 \mathrm{~h}$, para evitar regurgitações. As bandejas sob o piso das gaiolas foram revestidas com plástico, semelhante ao experimento 1, e a coleta de excretas, realizada duas vezes ao dia (8 e $16 \mathrm{~h}$ ), para evitar fermentações, por um período de 56 horas, após iniciado 
o fornecimento dos alimentos. As excretas foram acondicionadas e analisadas conforme descrito para o experimento 1. Os valores energéticos foram calculados pelas fórmulas:

EMA $(\mathrm{kcal} / \mathrm{kg}$ de MS $)=$ energia bruta $(\mathrm{EB})$ ingerida EB excretada MS ingerida

EMAn do alimento $=$ EB ingerida $-($ EB excretada + $\underline{8,22 * \text { balanço de nitrogênio }(\mathrm{BN})}$ MS ingerida

$\operatorname{EMV}(\mathrm{kcal} / \mathrm{kg}$ de MS $)=\mathrm{EB}$ ingerida $-(\mathrm{EB}$ excretada EB do endógeno) MS ingerida

EMVn do alimento $=\mathrm{EB}$ ingerida $-(\mathrm{EB}$ excretada $\mathrm{EB}$ do endógeno $+8,22 * \mathrm{BNV})$, MS ingerida

em que: $\mathrm{BNV}=\mathrm{BN}$ verdadeiro $=(\mathrm{N}$ ingerido $-(\mathrm{N}$ excretado - $\mathrm{N}$ endógeno)).

Após determinada a composição química das amostras de milho e subprodutos, e obtidos os valores energéticos (EMAn e EMVn), determinados nos experimentos 1 e 2 , foram estimadas equações para predizer a energia metabolizável deste grupo de alimentos, por intermédio de regressões lineares simples e múltiplas, utilizando o Método de Eliminação Indireta ou Backward, pelo pacote SAEG - versão 5.0 (Sistema para Análises Estatísticas - UFV, 1992). Utilizaram-se na predição das equações os valores de proteína bruta (PB), fibra bruta (FB) (ou fibra em detergente ácido - FDA e neutro - FDN), extrato etéreo (EE), matéria mineral (MM), amido, DGM e a densidade dos alimentos testados. Para obter equações de maior precisão, foram adotados o teste de $\mathrm{T}$ e significância de $5 \%$ de probabilidade para cada variável componente do modelo. Somente foram consideradas as equações em que todas as variáveis independentes apresentassem significância no modelo.

\section{Resultados e Discussão}

A composição química, a densidade e o diâmetro geométrico médio (DGM) dos 11 alimentos avaliados encontram-se na Tabela 2 e a composição em macro e microminerais, na Tabela 3. Quando comparados com a literatura, observam-se variações entre os valores de composição química analisados e aqueles relatados, tanto nas tabelas editadas no Brasil (ROSTAGNO et al., 1983; EMBRAPA, 1991; BRASIL, 1996) quanto naquelas da literatura estrangeira (JANSSEN, 1989; NRC, 1994; LEESON e SUMMERS, 1997; DALE, 1999; BATH et al., 1999). No entanto, as diferenças observadas eram de se esperar, uma vez que mudanças nas condições de solo, clima e cultivares, além dos subprodutos que são obtidos em várias condições de processamento e manejo, podem afetar a composição dos alimentos (ALBINO e SILVA, 1996; DALE, 1999; BATH et al., 1999). Segundo BATH et al. (1999), os valores apresentados em tabelas devem ser utilizados como um guia para obtenção da composição do alimento, e não uma informação precisa desta.

Quando se compara a composição dos milhetos com as amostras do milho, pode-se notar que, exceto a energia bruta, o amido e a densidade, que foram semelhantes, em média, e o DGM, que foi inferior ao milho pré-cozido, os demais componentes do milheto foram superiores, cujos teores em proteína bruta e extrato etéreo foram, em média, 51,76 e 95,31\% superiores à média das quatro amostras de milho (1, 2, QPM e pré-cozido).

Nota-se que a composição em macro e microminerais do milheto também apresentou tendência de ser maior que a do milho, com exceção do cálcio e selênio, cuja concentração foi semelhante, e do fósforo da amostra de milheto 2, o qual foi inferior. Por outro lado, o farelo de glúten 21 apresentou em sua composição elevados teores de minerais, quando comparados aos milhos e outros alimentos, excedendo somente no teor de cobre, no qual o farelo de glúten 21 foi o mais baixo (2,03 ppm).

Conforme mencionado por NUNES (1999), os alimentos podem ser classificados quanto ao seu diâmetro geométrico médio (DGM), com alimentos de DGM grosso (maior que 832,7 mm), médio (entre 375,3 e $832,7 \mathrm{~mm}$ ) e fino (menor que $375,3 \mathrm{~mm}$ ). Assim, nota-se que as duas amostras de milho (1 e 2) e o gérmen de milho podem ser classificados, no presente trabalho, como alimento de DGM grosso e o gérmen de milho fino como um alimento de DGM fino. Os demais alimentos estudados apresentaram DGM médio e, surpreendentemente, o gérmen de milho comum apresentou um DGM 90,5\% superior ao gérmen de milho desengordurado.

O farelo de glúten 21 destacou-se como um alimento fibroso $(6,64 \%)$, quando comparado às amostras de milho e demais subprodutos, apresentando 
Tabela 2 - Composição química e física do milho e subprodutos e do milheto

Table 2 - Chemical and phisical composition of the corn and byproducts and the millet

\begin{tabular}{|c|c|c|c|c|c|c|c|c|c|c|c|}
\hline \multirow[b]{2}{*}{$\begin{array}{l}\text { Alimento } \\
\text { Feedstuffs }\end{array}$} & \multicolumn{11}{|c|}{$\begin{array}{c}\text { Composição }{ }^{1,2} \\
\text { Composition }\end{array}$} \\
\hline & $\begin{array}{l}\text { MS } \\
D M \\
(\%) \\
\end{array}$ & $\begin{array}{l}\mathrm{PB} \\
C P \\
(\%) \\
\end{array}$ & $\begin{array}{c}\mathrm{EE} \\
E E \\
(\%) \\
\end{array}$ & $\begin{array}{l}\text { MM } \\
\text { Ash } \\
(\%) \\
\end{array}$ & $\begin{array}{l}\text { FB } \\
C F \\
(\%) \\
\end{array}$ & $\begin{array}{l}\text { FDA } \\
A D F \\
(\%) \\
\end{array}$ & $\begin{array}{l}\text { FDN } \\
N D F \\
(\%) \\
\end{array}$ & $\begin{array}{c}\mathrm{EB} \\
G E \\
(\mathrm{kcal} / \mathrm{kg}) \\
\end{array}$ & $\begin{array}{c}\text { Amido } \\
\text { Starch } \\
(\%) \\
\end{array}$ & $\begin{array}{l}\text { Dens. } \\
\text { Dens. } \\
(\mathrm{g} / \mathrm{L})\end{array}$ & $\begin{array}{c}\text { DGM } \\
M G D \\
\mathrm{~mm} \\
\end{array}$ \\
\hline $\begin{array}{l}\text { Milho } 1 \\
\text { Corn 1 }\end{array}$ & 87,86 & 9,82 & 1,88 & 0,88 & 0,78 & 5,13 & 14,22 & 3929 & 66,25 & 724,5 & 874,5 \\
\hline $\begin{array}{l}\text { Milho } 2 \\
\text { Corn } 2\end{array}$ & 86,65 & 8,07 & 2,46 & 1,20 & 0,75 & 2,41 & 11,12 & 3713 & 73,45 & 757,7 & 904,1 \\
\hline $\begin{array}{l}\text { Milho QPM } \\
\text { Quality Protein Maize }\end{array}$ & 88,52 & 7,67 & 3,79 & 0,92 & 1,00 & 2,70 & 12,31 & 3907 & 66,38 & 653,0 & 759,2 \\
\hline $\begin{array}{l}\text { Milho pré-cozido } \\
\text { Pre-cooked corn }\end{array}$ & 88,82 & 8,43 & 1,66 & 0,93 & 1,22 & 3,19 & 9,67 & 3930 & 61,00 & 701,7 & 387,1 \\
\hline $\begin{array}{l}\text { Farelo de glúten } 60 \\
\text { Corn gluten feed }\end{array}$ & 92,09 & 62,15 & 4,06 & 1,24 & 0,02 & 17,68 & 3,32 & 5247 & 13,75 & 772,7 & 494,7 \\
\hline $\begin{array}{l}\text { Farelo de glúten } 21 \\
\text { Corn gluten meal }\end{array}$ & 85,59 & 24,00 & 3,20 & 7,15 & 6,64 & 11,14 & 38,75 & 3812 & 26,58 & 433,3 & 728,3 \\
\hline $\begin{array}{l}\text { Gérmen milho (GM) } \\
\text { Corn germ - CG }\end{array}$ & 89,47 & 8,96 & 5,76 & 2,08 & 1,59 & 3,33 & 16,44 & 4033 & 57,87 & 612,1 & 1333,8 \\
\hline $\begin{array}{l}\text { Gérmen de milho fino } \\
\text { Fine corn germ }\end{array}$ & 90,65 & 9,73 & 8,24 & 3,28 & 1,32 & 2,00 & 12,54 & 4329 & 44,23 & 495,5 & 321,2 \\
\hline $\begin{array}{l}\text { GM desengordurado } \\
\text { Free-fat } C G\end{array}$ & 90,16 & 10,85 & 1,29 & 6,59 & 2,78 & 6,77 & 2,78 & 3543 & 51,57 & 706,2 & 700,1 \\
\hline $\begin{array}{l}\text { Milheto } 1 \\
\text { Millet } 1\end{array}$ & 89,47 & 12,40 & 4,90 & 1,83 & 2,94 & 7,65 & 17,58 & 3966 & 66,01 & 662,1 & 718,8 \\
\hline $\begin{array}{l}\text { Milheto } 2 \\
\text { Millet } 2\end{array}$ & 88,52 & 13,41 & 4,67 & 1,33 & 4,64 & 10,03 & 21,08 & 4024 & 63,37 & 759,3 & 783,3 \\
\hline
\end{tabular}

${ }^{1}$ Análises realizadas no Laboratório de Nutrição Animal do DZO da Universidade Federal de Lavras (UFLA).

${ }^{2}$ MS - matéria seca; PB - proteína bruta; EE - extrato etéreo; MM - matéria mineral; FB - fibra bruta; FDA - fibra em detergente ácido; FDN - fibra em detergente neutro; EB - energia bruta; Dens. - densidade e DGM - diâmetro geométrico médio.

${ }_{1}^{1}$ Realized in the Animal Nutrition Laboratory of the Federal University of Lavras (UFLA).

2 DM - dry matter; CP - crude protein; EE - etherial extract; CF - crude fiber; ADF - acid detergent fiber; NDF - neutral detergent fiber; GE - gross energy; Dens. - density; $M G D$-medium geometric diameter.

menor densidade $(433,3 \mathrm{~g} / \mathrm{L})$ que os demais alimentos. O farelo de glúten 60 , por outro lado, apresentou maior densidade $(772,7 \mathrm{~g} / \mathrm{L})$ e menores teores de fibra bruta $(0,02 \%)$ e amido $(13,75 \%)$. Este resultado era de se esperar, uma vez que, conforme BRASIL (1998), para obtenção deste subproduto, há remoção da maior parte do amido, gérmen e porções fibrosas.

Dos alimentos analisados, somente o gérmen desengordurado apresentou um elevado teor de cálcio. Este subproduto é obtido por processo industrial para extração de óleo contido no gérmen do milho integral (BRASIL, 1998), sendo que este maior conteúdo de cálcio (e mesmo matéria mineral) possivelmente estaria associado ao processo de extração de óleo. O gérmen desengordurado também apresentou um teor de proteína $21,09 \%$ maior que o gérmen comum e $11,51 \%$ que o gérmen fino. No entanto, vale ressaltar que os diferentes métodos de processamento industrial dos subprodutos podem alterar sua composição (ALBINO et al., 1992a; BATH et al., 1999), levando a diferenças quando comparados entre si.

Os valores energéticos determinados com pintos (Tabela 4) mostraram haver alguma variação, quando comparado com a literatura nacional (ROSTAGNO et al., 1983; ALBINO et al., 1989; ALBINO et al., 1992a; EMBRAPA, 1991; FISCHER et al., 1998) e a literatura estrangeira(JANSSEN, 1989; NRC, 1994; DALE, 1999).

À exceção do farelo de glúten 21 e do gérmen de milho desengordurado, que apresentaram valores energéticos mais baixos, e do farelo de glúten 60 , cujos valores de energia metabolizável determinados (EMA, EMAn, EMV, EMVn) foram maiores, os demais alimentos apresentaram valores relativamente similares, em que os valores de EMAn e EMVn do gérmen de milho foram 12,23 e 12,62\% inferiores ao milho pré-cozido $(3272 \mathrm{kcal}$ de EMAn, $3323 \mathrm{kcal}$ de EMVn $/ \mathrm{kg}$ de MS e $3728 \mathrm{kcal}$ de EMAn e $3803 \mathrm{kcal}$ de EMVn/kg de MS, respectivamente).

Quando se compara a média dos valores de EMA e EMV com as de EMAn e EMVn, observa-se que há 
Tabela 3 - Composição de macro e microminerais do milho e subprodutos e do milheto

Table 3 - Macro and trace elements of the corn and byproducts and the millet

\begin{tabular}{|c|c|c|c|c|c|c|c|c|c|c|}
\hline \multirow[b]{2}{*}{$\begin{array}{l}\text { Alimento } \\
\text { Feedstuffs }\end{array}$} & \multicolumn{10}{|c|}{$\begin{array}{c}\text { Composição }^{1} \\
\text { Composition }^{-1}\end{array}$} \\
\hline & $\begin{array}{l}\mathrm{Ca} \\
(\%)\end{array}$ & $\begin{array}{c}\mathrm{P} \\
(\%)\end{array}$ & $\begin{array}{c}\mathrm{K} \\
(\%)\end{array}$ & $\begin{array}{l}\mathrm{Mg} \\
(\%)\end{array}$ & $\begin{array}{c}\mathrm{Na} \\
(\mathrm{ppm})\end{array}$ & $\begin{array}{c}\mathrm{Fe} \\
(\mathrm{ppm})\end{array}$ & $\begin{array}{c}\mathrm{Zn} \\
(\mathrm{ppm})\end{array}$ & $\begin{array}{c}\mathrm{Mn} \\
(\mathrm{ppm})\end{array}$ & $\begin{array}{c}\mathrm{Cu} \\
(\mathrm{ppm})\end{array}$ & $\begin{array}{r}\mathrm{Se}^{2} \\
(\mathrm{ppb})\end{array}$ \\
\hline $\begin{array}{l}\text { Milho 1 } \\
\text { Corn 1 }\end{array}$ & 0,07 & 0,19 & 0,16 & 0,06 & 32,39 & 29,16 & 24,87 & 12,51 & 2,73 & 58 \\
\hline $\begin{array}{l}\text { Milho } 2 \\
\text { Corn } 2\end{array}$ & 0,03 & 0,21 & 0,27 & 0,06 & 39,17 & 53,78 & 22,10 & 12,13 & 3,35 & 71 \\
\hline $\begin{array}{l}\text { Milho QPM } \\
\text { Quality protein maize }\end{array}$ & 0,04 & 0,13 & 0,21 & 0,05 & 91,28 & 53,38 & 17,57 & 10,32 & 2,58 & 49 \\
\hline $\begin{array}{l}\text { Milho pré-cozido } \\
\text { Pre-cooked corn }\end{array}$ & 0,04 & 0,20 & 0,20 & 0,06 & 64,87 & 51,30 & 21,80 & 11,40 & 2,68 & 34 \\
\hline $\begin{array}{l}\text { Farelo de glúten } 60 \\
\text { Corn gluten feed }\end{array}$ & 0,03 & 0,39 & 0,07 & 0,03 & 56,17 & 114,28 & 19,34 & 2,39 & 10,77 & 108 \\
\hline $\begin{array}{l}\text { Farelo de glúten } 21 \\
\text { Corn gluten meal }\end{array}$ & 0,05 & 0,39 & 1,49 & 0,34 & 107,73 & 239,30 & 90,94 & 30,56 & 2,03 & 114 \\
\hline $\begin{array}{l}\text { Gérmen de milho (GM) } \\
\text { Corn germ - } C G\end{array}$ & 0,03 & 0,37 & 0,45 & 0,13 & 52,19 & 69,28 & 41,12 & 12,71 & 7,57 & 43 \\
\hline $\begin{array}{l}\text { Gérmen de milho fino } \\
\text { Fine corn germ }\end{array}$ & 0,04 & 0,62 & 0,79 & 0,20 & 98,52 & 80,49 & 67,12 & 19,92 & 11,35 & 149 \\
\hline $\begin{array}{l}\text { GM desengordurado } \\
\text { Free-fat } C G\end{array}$ & 0,74 & 0,73 & 0,77 & 0,51 & 62,08 & 207,15 & 53,44 & 27,33 & 7,52 & 104 \\
\hline $\begin{array}{l}\text { Milheto } 1 \\
\text { Millet } 1\end{array}$ & 0,03 & 0,26 & 0,34 & 0,10 & 78,48 & 169,05 & 36,47 & 19,05 & 9,30 & 63 \\
\hline $\begin{array}{l}\text { Milheto } 2 \\
\text { Millet } 2\end{array}$ & 0,02 & 0,18 & 0,31 & 0,08 & 70,37 & 76,14 & 35,43 & 23,35 & 8,93 & 52 \\
\hline
\end{tabular}

1 Análises realizadas no Laboratório de Nutrição Animal do DZO/UFLA - Lavras/MG.

2 Análises realizadas no Laboratório do Instituto de Pesquisas Energéticas e Nucleares (INPE) - USP/SP.

1 Analyses performed at the Animal Nutrition Laboratory of the Federal University of Lavras (UFLA).

2 Analyses performed the Nuclear and Energetics Institut Laboratory - USP/SP.

uma redução de 68 e $87 \mathrm{kcal} / \mathrm{kg}$ de MS, correspondendo a 2,01 e 2,51\%, respectivamente, quando se aplica a correção para o balanço de nitrogênio. Estes percentuais são inferiores àqueles de 6,88 e $6,38 \%$, observados nos trabalhos de ALBINO et al. (1992a) e os de BORGES et al. (1998a), nos quais se constata um percentual de 6,04 e $5,89 \%$, quando os valores energéticos foram obtidos com aves de 13 dias de idade, e 4,95 e 4,69\%, quando as aves tinham 39 dias, respectivamente, para as diferenças entre as determinações sem correção e aquelas corrigidas para o balanço de nitrogênio. Os valores obtidos por BORGES et al. (1998a) mostraram haver uma tendência de redução no percentual de correção pelo nitrogênio retido, com o avanço na idade das aves (13 e 39 dias). Entretanto, os baixos percentuais obtidos no presente trabalho foram obtidos com aves no período de 22 a 26 dias de idade.

A EMVn média foi $61 \mathrm{kcal} / \mathrm{kg}$ de MS maior que a EMAn, mostrando a influência das energias fecal metabólica e urinária endógena sobre os valores energéticos dos alimentos. De acordo com LECLERCQ et al. (1999), a energia verdadeira é de 5 a $10 \%$ superior à aparente, sendo esta diferença influenciada pelo consumo. No presente trabalho, a diferença observada foi de $1,84 \%$, destacando-se que, no método tradicional com pintos, o consumo foi normal, uma vez que as aves receberam alimentação à vontade.

A repetibilidade média em todas as determinações foi de 0,97 , sendo semelhantes àquelas encontradas por ALBINO et al. (1992a). Segundo o referido autor, esta repetibilidade mede a correlação entre as observações de um mesmo alimento, mostrando, então, uma boa correlação entre as estimativas da energia neste ensaio com pintos em crescimento. LIMA et al. (1989) encontraram maior repetibilidade $(0,99)$ na determinação dos valores energéticos de alguns alimentos, quando utilizaram o método tradicional de coleta de excretas, com pintos em crescimento.

O valor médio da EMAn das amostras de milho (1, 2 e QPM) obtido no presente experimento (3625 kcal $/ \mathrm{kg}$ de MS) foi inferior àquele apresentado por ROSTAGNO et al. (1983); ALBINO et 
Tabela 4 - Valores energéticos do milho, subprodutos e do milheto, determinados com pintos (22 a 26 dias de idade) e galos adultos (18 meses de idade), e seus respectivos desvios-padrão (valores expressos na matéria seca)

Table 4 - Energy values of the corn, byproducts and the millet, determined with chicks (22 to 26 days of age) and adult cockerels (18 months of age), and its respective standard errors (based on dry matter values)

\begin{tabular}{|c|c|c|c|c|c|c|c|c|}
\hline \multirow[t]{2}{*}{$\begin{array}{l}\text { Alimento } \\
\text { Feedstuff }\end{array}$} & \multicolumn{2}{|c|}{$\begin{array}{c}\mathrm{EMA}(\mathrm{kcal} / \mathrm{kg})^{1} \\
A M E\end{array}$} & \multicolumn{2}{|c|}{$\begin{array}{c}\text { EMAn }(\mathrm{kcal} / \mathrm{kg})^{1} \\
A M E n\end{array}$} & \multicolumn{2}{|c|}{$\begin{array}{c}\mathrm{EMV}(\mathrm{kcal} / \mathrm{kg})^{1} \\
T M E\end{array}$} & \multicolumn{2}{|c|}{$\begin{array}{c}\mathrm{EMVn}(\mathrm{kcal} / \mathrm{kg})^{1} \\
T M E n\end{array}$} \\
\hline & $\begin{array}{l}\text { Pintos } \\
\text { Chicks }\end{array}$ & $\begin{array}{c}\text { Galos } \\
\text { Cockerels }\end{array}$ & $\begin{array}{l}\text { Pintos } \\
\text { Chicks }\end{array}$ & $\begin{array}{c}\text { Galos } \\
\text { Cockerels }\end{array}$ & $\begin{array}{l}\text { Pintos } \\
\text { Chicks }\end{array}$ & $\begin{array}{c}\text { Galos } \\
\text { Cockerels }\end{array}$ & $\begin{array}{l}\text { Pintos } \\
\text { Chicks }\end{array}$ & $\begin{array}{c}\text { Galos } \\
\text { Cockerels }\end{array}$ \\
\hline $\begin{array}{l}\text { Milho } 1 \\
\text { Corn } 1\end{array}$ & $3749(43)$ & $3444(90)$ & $3699(40)$ & $3736(32)$ & $3822(44)$ & $4270(90)$ & $3755(41)$ & $4015(32)$ \\
\hline $\begin{array}{l}\text { Milho } 2 \\
\text { Corn } 2\end{array}$ & $3573(72)$ & $3028(45)$ & $3529(72)$ & $3419(55)$ & $3647(74)$ & $3866(45)$ & $3586(72)$ & $3701(55)$ \\
\hline $\begin{array}{l}\text { Milho QPM } \\
\text { Quality protein maize }\end{array}$ & $3691(105)$ & $3289(84)$ & $3647(103)$ & $3627(56)$ & $3765(113)$ & $4109(84)$ & 3703(109) & $3903(56)$ \\
\hline $\begin{array}{l}\text { Milho pré-cozido } \\
\text { Pre-cooked corn }\end{array}$ & $3771(172)$ & $3293(85)$ & $3728(164)$ & 3581(39) & 3868(179) & $4111(85)$ & 3803(170) & $3856(39)$ \\
\hline $\begin{array}{l}\text { Farelo de glúten } 60 \\
\text { Corn gluten feed }\end{array}$ & 4314(91) & $3772(64)$ & 4108(93) & 3982(17) & 4420(93) & $4561(64)$ & $4190(95)$ & $4248(17)$ \\
\hline $\begin{array}{l}\text { Farelo de glúten } 21 \\
\text { Corn gluten meal }\end{array}$ & $2025(142)$ & $1638(84)$ & $1937(134)$ & 1961(88) & 2093(138) & $2460(130)$ & 1990(130) & $2246(88)$ \\
\hline $\begin{array}{l}\text { Gérmen de milho(GM) } \\
\text { Corn germ - CG }\end{array}$ & $3316(81)$ & $3134(104)$ & $3272(78)$ & $3509(60)$ & $3381(83)$ & $3945(104)$ & $3323(80)$ & $3782(60)$ \\
\hline $\begin{array}{l}\text { Gérmen de milho fino } \\
\text { Fine corn germ - CG }\end{array}$ & $3640(98)$ & $3389(88)$ & $3588(99)$ & $3692(42)$ & $3716(101)$ & $4190(88)$ & $3646(102)$ & $3962(42)$ \\
\hline $\begin{array}{l}\text { GM desengordurado } \\
\text { Free-fat } C G\end{array}$ & $2498(111)$ & $2125(95)$ & 2448(109) & 2458(94) & $2585(101)$ & $2930(95)$ & 2515(101) & $2729(94)$ \\
\hline $\begin{array}{l}\text { Milheto } 1 \\
\text { Millet } 1\end{array}$ & $3323(162)$ & 3058(39) & $3248(158)$ & $3446(17)$ & 3401(171) & $3870(39)$ & $3308(165)$ & $3719(17)$ \\
\hline $\begin{array}{l}\text { Milheto } 2 \\
\text { Millet } 2\end{array}$ & $3400(96)$ & $3246(78)$ & 3347(89) & $3528(56)$ & $3476(85)$ & $4066(78)$ & 3406(81) & $3804(56)$ \\
\hline $\begin{array}{l}\text { Médias } \\
\text { Means }\end{array}$ & $3391(617)$ & $3038(681)$ & $3323(605)$ & $3358(582)$ & $3471(622)$ & $3852(599)$ & $3384(609)$ & $3633(579)$ \\
\hline $\begin{array}{l}\text { Repetibilidade média } \\
\text { Mean repeatibility }\end{array}$ & 0,969 & 0,983 & 0,970 & 0,991 & 0,969 & 0,981 & 0,969 & 0,991 \\
\hline $\mathrm{CV}(\%)$ & 3,33 & 2,64 & 3,29 & 1,67 & 3,29 & 2,22 & 3,27 & 1,54 \\
\hline
\end{tabular}

al. (1989); EMBRAPA (1991); ALBINO et al. (1992a); NRC (1994); NASCIMENTO et al. (1998), de 3904, 3712, 3786, 3810, 3764 e $3783 \mathrm{kcal}$ de EMAn/kg de MS, respectivamente. Esta diferença, também observada quando se compara a literatura referenciada, reforça as colocações de LEESON et al. (1993), de que os valores energéticos de diferentes partidas de milho são variáveis.

Dados de BAIDOO et al. (1991) mostraram que há redução linear no conteúdo de amido e no valor energético (EMAn) do milho, associada a uma variação na sua densidade. No presente trabalho, a amostra de milho 1 apresentou densidade 4,38 e teor de amido $9,80 \%$ menor que a amostra 2 ; no entanto, a EMAn da amostra 2 foi $4,60 \%$ inferior $(170 \mathrm{kcal} / \mathrm{kg}$ de MS), contradizendo, de certa forma, os referidos autores. Convém ressaltar que a proteína e energia brutas do milho 1, entretanto, foram 17,82 e 4,18\% maiores, o que pode ter contribuído para o maior valor energético deste alimento. Independentemente desta observação, ROSTAGNO e SILVA (1997) relataram que os nutricionistas devem estar atentos para estas possíveis alterações no valor nutricional dos alimentos, fazendo as modificações necessárias, permitindo assim um processo de formulação de rações com maior acurácia. De maneira geral, os valores de EMVn determinados neste ensaio parecem estar mais próximos daqueles de EMAn apresentados na literatura citada anteriormente.

Os valores de EMA, EMAn, EMV e EMVn determinados com galos adultos também encontram- 
se na Tabela 4. Nota-se que os valores de EMA e EMAn foram inferiores àqueles de EMV e EMVn, sendo coerentes com aqueles relatados por ALBINO et al. (1989) e ALBINO et al. (1992a). Entretanto, quando se aplica a correção para o balanço de nitrogênio, nota-se que a variação entre EMAn e EMVn é bem menor $(8,19 \%)$ que aquela observada entre EMA e EMV (26,79\%). Assim como encontrado pelos autores referenciados acima, os valores de EMA foram bem inferiores àqueles de EMAn, atribuindo-se esta inferioridade ao balanço negativo de nitrogênio, haja vista o período de jejum ao qual os galos foram submetidos (ALBINO et al, 1989). Estas observações são contrárias às obtidas por BORGES et al. (1998a,b), cujos valores de EMA foram superiores aos de EMAn. Pequena diferença $(0,94 \%)$ da EMA sobre a EMAn foi observada nos dados de RAGLAND et al. (1997), quando determinaram valores energéticos do milho, da cevada, do milheto, sorgo e triticale, utilizando patos adultos.

Por outro lado, quando se observam os valores de EMV e EMVn, nota-se certa superioridade do valor médio da EMV em relação à média da $\operatorname{EMVn~(5,69\% ).~}$ Este percentual está de acordo com aquele observado (5,30\%) nos resultados de ALBINO et al. (1992a) e inferior àquele que obtido $(9,31 \%)$ dos valores médios de FISCHER JR. et al. (1998). De maneira geral, outros resultados encontrados na literatura mostram o mesmo comportamento (DALE e FULLER, 1984; ALBINO et al., 1989; RAGLAND et al., 1997; BORGES et al., 1998a,b). De acordo com WOLYNETZ e SIBBALD (1984), esta diferença entre a EMV e a EMVn é atribuída à maior perda de nitrogênio endógeno pelas aves em jejum em comparação àquelas que estão recebendo os alimentos. As perdas endógenas e metabólicas medidas em aves em jejum são maiores que aquelas usadas para se determinar a EMV. Segundo DALE e FULLER (1984), o balanço de nitrogênio negativo das aves jejuadas, quando multiplicado pelo fator de correção, reduz a estimativa da energia endógena perdida, normalmente em mais de 50\%. Assim, em virtude deste valor ser subtraído da energia da excreta de aves alimentadas, os valores de EMVn tornam-se menores que os de EMV.

O valor médio da EMVn das amostras de milho 1, 2 e QPM (3873 kcal/kg de MS) foram inferiores àqueles relatados por ALBINO et al. (1989), ALBINO et al. (1992b) e FISCHER JR. et al. (1998), de 4010, 3940 e $3937 \mathrm{kcal}$ de EMVn/kg de MS, respectivamente. Quando comparada aos valo- res de EMAn apresentados nas tabelas nacionais, nota-se que a média obtida no presente ensaio foi inferior (31 kcal $/ \mathrm{kg}$ de MS) à apresentada por ROSTAGNO et al. (1983) (3904 kcal de EMAn/kg de MS) e semelhante àquela contida na tabela da EMBRAPA (1991) (3876 kcal de EMAn/kg de MS). O milho pré-cozido apresentou um valor de EMVn bem similar (3856 kcal/kg de MS) à média das amostras de milho. Quando comparada às tabelas estrangeiras, a EMVn média dos milhos foi inferior ao valor do NRC (1994) em $26 \mathrm{kcal} / \mathrm{kg}$ de MS e semelhante àquela de EMAn descrita por DALE (1999). A EMVn do farelo de glúten 21, relacionada à EMAn citada por DALE (1999), foi $12,92 \%$ superior (1989 $\mathrm{kcal}$ de EMAn/kg de MS x $2246 \mathrm{kcal}$ de EMVn/kg de MS).

A EMVn determinada no presente ensaio para o farelo de glúten 60 foi 1,48\% inferior ao valor obtido por ALBINO et al. (1989), 6,31\% superior àquele relatado por FISCHER JR. et al. (1998) e 2,21\% superior à EMAn descrita recentemente por DALE (1999). O milheto, por sua vez, teve uma EMVn média (3762 kcal $/ \mathrm{kg}$ ) 3,00\% menor que aquela $(3875 \mathrm{kcal} / \mathrm{kg})$ descrita por RAGLAND et al. (1997), determinada com patos adultos.

Com exceção do gérmen desengordurado, com valor energético (2729 $\mathrm{kcal}$ de EMVn/kg de MS) mais baixo, as demais amostras de gérmen de milho apresentaram EMVn média semelhante à dos milhos (3872 x $3873 \mathrm{kcal} / \mathrm{kg}$ de MS, respectivamente). O resultado observado para o gérmen desengordurado era esperado, uma vez que o processo de desengorduramento resultou em baixo teor de extrato etéreo nesta amostra $(1,29 \%)$, quando comparada às demais $(5,76$ e $8,24 \%$, respectivamente, para o gérmen comum e o gérmen de milho fino).

De maneira geral, quando se observam as determinações dos valores energéticos com galos adultos, pode-se constatar que a repetibilidade média da EMVn foi superior àquela obtida no método tradicional com pintos em crescimento $(0,991 \times 0,969)$, mostrando boa correlação nas observações de cada alimento. Estes valores encontrados para a repetibilidade média foram superiores àqueles descritos por ALBINO et al. (1992a), que encontraram um valor de 0,979, quando trabalharam com galos adultos, usando o método de alimentação forçada.

$\mathrm{Na}$ Tabela 5 estão apresentadas as equações calculadas para estimar os valores de EMAn determinadas com pintos e de EMVn com galos adultos, do milho e de alguns subprodutos do milho. 
No geral, observou-se que as equações com maior número de variáveis no modelo apresentaram coeficientes de determinação $\left(\mathrm{R}^{2}\right)$ mais elevados, sendo 0,98 (EMAn) e 0,99 (EMVn) para as equações com sete variáveis, comparadas a 0,92 (EMAn), 0,91 e 0,86 (EMVn) nas equações com uma variável apenas. Somente foram consideradas as equações em que todos os componentes do modelo apresentassem significância a $5 \%$ de probabilidade no teste $\mathrm{T}$. Deve-se salientar, porém, que equações com grande número de variáveis, apesar de mais precisas nas estimativas, podem se tornar inviabilizadas, já que a determinação de componentes, como o DGM e a densidade dos alimentos, em condições práticas, muitas vezes não é possível. Assim, o uso de equações com menor número de variáveis apresenta, em relação às outras, maior facilidade por necessitarem de algumas análises, muitas vezes de rotina em laboratórios, que demandam menor tempo e facilidade na determinação (NUNES, 1999).

A matéria mineral foi a variável que melhor se correlacionou com os valores energéticos, participando de praticamente todas as equações estimadas, exceto naquela em que a FDN participou isoladamente. Ape- sar de se correlacionar negativamente ao conteúdo de energia dos alimentos, a correlação da MM com as EMAn e EMVn foi alta, correspondendo a 92,9 e 92,7 $\%$, respectivamente. Recentemente, NUNES (1999) concluiu que as equações contendo as variáveis $\mathrm{PB}$ e FDN foram melhores na estimativa da EM. No entanto, o referido autor também observou que a MM e o EE foram boas variáveis para predizer o conteúdo energético dos alimentos. O NRC (1994) apresenta equações para predizer a EMAn do milho e do farelo de glúten 60 com as variáveis $\mathrm{PB}, \mathrm{EE}$ e extrato não nitrogenado. Para o farelo de glúten 21, a equação ficou composta com a MM, PB, EE e FB.

No presente trabalho nota-se que as equações com as variáveis PB, FB ou FDN, MM e amido (Tabela 6) apresentaram bons ajustes, com elevados valores de $\mathrm{R}^{2}$, mostrando que mais de $96 \%$ da variabilidade nos valores de EMAn determinados com pintos em crescimento é explicada por estas variáveis. Quando se observa a média da soma do quadrado dos desvios das estimativas, nota-se que há um aumento desta, à medida que se diminui o $\mathrm{R}^{2}$. Logicamente, maiores valores do coeficiente de determinação representam melhor explicação das variações.

Tabela 5 - Equações de predição dos valores energéticos do milho e subprodutos, determinados com pintos em crescimento (EMAn) e galos adultos (EMVn), em função da composição dos alimentos e suas respectivas correlações (valores expressos com base na matéria seca)

Table 5 - Prediction equations of the energetic values of the corn and byproducts, determined with growing chickens (AMEn) and adult cockerels (TMEn), based on feedstuffs composition and respective correlations (data based on dry matter)

\begin{tabular}{|c|c|c|c|c|c|c|c|c|c|c|}
\hline $\begin{array}{l}\text { Constante } \\
\text { Constant }\end{array}$ & $\begin{array}{c}\text { PB } \\
(\%) \\
C P\end{array}$ & $\begin{array}{c}\text { FB } \\
(\%) \\
C F\end{array}$ & $\begin{array}{c}\text { FDA } \\
(\%) \\
A D F\end{array}$ & $\begin{array}{c}\text { FDN } \\
(\%) \\
N D F\end{array}$ & $\begin{array}{c}\mathrm{EE} \\
(\%) \\
E E\end{array}$ & $\begin{array}{l}\mathrm{MM} \\
(\%) \\
\text { Ash }\end{array}$ & $\begin{array}{c}\text { Amido } \\
(\%) \\
\text { Starch }\end{array}$ & $\begin{array}{c}\text { Dens. } \\
(\mathrm{g} / \mathrm{L})\end{array}$ & $\begin{array}{l}\text { DGM } \\
\mathrm{m} m\end{array}$ & $\mathrm{R}^{2}$ \\
\hline & \multicolumn{10}{|c|}{$\begin{array}{l}\text { EMAn (Pintos) } \\
\text { AMEn (Chickens) }\end{array}$} \\
\hline$-4403,76$ & ---- & ---- & $-161,48$ & $+198,24$ & $+393,53$ & $-687,19$ & $-49,98$ & $+15,19$ & $-1,78$ & 0,98 \\
\hline$+4887,27$ & $-5,42$ & ---- & --- & $-32,74$ & --- & $-127,52$ & $-8,15$ & --- & --- & 0,97 \\
\hline$+5167,33$ & $-8,62$ & $-131,97$ & --- & --- & ---- & $-183,43$ & $-14,71$ & ---- & ---- & 0,97 \\
\hline$+4466,32$ & --- & ---- & ---- & $-33,51$ & ---- & $-109,11$ & $-3,33$ & ---- & ---- & 0,97 \\
\hline$+4281,55$ & ---- & ---- & ---- & $-39,97$ & ---- & $-72,90$ & --- & ---- & ---- & 0,96 \\
\hline$+4354,77$ & ---- & $-112,05$ & ---- & --- & ---- & $-151,74$ & ---- & ---- & $-0,464$ & 0,95 \\
\hline Correlações & 0,1649 & $-0,9192$ & $-0,1328$ & $-0,9702$ & 0,1785 & $-0,9289$ & 0,1837 & 0,5799 & $-0,1944$ & ---- \\
\hline \multicolumn{11}{|l|}{ Correlations } \\
\hline & \multirow{2}{*}{\multicolumn{10}{|c|}{$\begin{array}{c}\text { EMVn(Galos) } \\
\text { TMEn (Cockerels) }\end{array}$}} \\
\hline & & & & & & & & & & \\
\hline$-10328,3$ & ---- & ---- & $-333,88$ & $+377,80$ & $+678,15$ & $-1135,41$ & $-99,82$ & $+27,17$ & $-2,62$ & 0,99 \\
\hline$+4187,17$ & $-59,69$ & ---- & $+203,81$ & $-54,71$ & $+117,61$ & $-107,70$ & --- & ---- & ---- & 0,99 \\
\hline$+5283,87$ & $-10,46$ & $-127,51$ & --- & --- & $+27,62$ & $-171,63$ & $-14,07$ & ---- & ---- & 0,99 \\
\hline$+4234,28$ & --- & -- & ---- & $-27,58$ & $+50,18$ & $-107,54$ & --- & ---- & ---- & 0,97 \\
\hline$+4485,13$ & ---- & ---- & ---- & $-34,20$ & --- & $-83,83$ & ---- & ---- & ---- & 0,94 \\
\hline$+4250,22$ & ---- & $-136,60$ & ---- & ---- & ---- & $-120,48$ & ---- & ---- & ---- & 0,91 \\
\hline Correlações & 0,1056 & $-0,9212$ & $-0,1957$ & $-0,9548$ & 0,2907 & $-0,9270$ & 0,2066 & 0,5077 & $-0,0997$ & ---- \\
\hline Correlations & & & & & & & & & & \\
\hline
\end{tabular}


Analisando-se a Tabela 7, nota-se que a equação com as variáveis PB, FDA, FDN, EE e MM explicaram mais de $99 \%$ da variação nos valores de EMVn, determinados com galos adultos $\left(\mathrm{R}^{2}=0,99\right)$, mostrando boas estimativas, o que pode ser observado por meio da média do somatório do quadrado dos desvios. Entretanto, observa-se também que as equações com FDN, EE e MM explicaram $97 \%$ do ajuste $\left(\mathrm{R}^{2}=0,97\right)$. SIBBALD et al. (1980) observaram que as equações com combinação das variáveis EE, FB e MM ou EE, PB e extratos não nitrogenados foram úteis na predição da EMV, explicando aproximadamente $80 \%$ da variação. Ao se compararem esses dados com os do presente trabalho, nota-se melhor ajuste das equações, as quais apresentaram maiores valores de $\mathrm{R}^{2}$. A equação com a variável MM isoladamente teve $\mathrm{R}^{2}$ equivalente a 0,86 , superior à variabilidade descrita por SIBBALD et al. (1980).

DOLZ e DE BLAS (1992) obtiveram boas predições da EMAn e EMVn da farinha de carne e ossos, quando utilizaram EE e PB no modelo. Já AZEVEDO (1996) notou melhor predição da energia, quando utilizou a PB e a proteína digestível em pepsina a $0,02 \%$. No entanto, é possível notar que as variáveis que fazem parte do modelo variam em função da origem e composição do alimento, ou grupo de alimentos para o qual as equações são estimadas.

Tabela 6 - Estimativas dos valores de EMAn do milho e subprodutos, determinadas com pintos, por meio das equações de predição dos valores energéticos, em função da composição dos alimentos (valores expressos em $\mathrm{kcal} / \mathrm{kg}$ de matéria seca)

Table 6 - Estimate of the AMEn values of corn and byproducts, determined with chickens, by the prediction equations of the energy values based on the food composition (data based on kcal/kg of the dry matter)

\begin{tabular}{|c|c|c|c|c|c|}
\hline \multicolumn{5}{|c|}{$\begin{array}{l}\text { EMAn }_{1}=4887,27-5,42 \mathrm{~PB}-32,74 \mathrm{FDN}-127,52 \mathrm{MM}-8,15 \mathrm{AMIDO} \\
\mathrm{EMAn}_{2}=5167,33-8,62 \mathrm{~PB}-131,97 \mathrm{FB}-183,43 \mathrm{MM}-14,71 \text { AMIDO } \\
\text { EMAn }_{3}=4466,32-33,51 \mathrm{FDN}-109,11 \mathrm{MM}-3,33 \mathrm{AMIDO} \\
\mathrm{EMAn}_{4}=4281,55-39,97 \mathrm{FDN}-72,90 \mathrm{MM}\end{array}$} & \multirow{2}{*}{$\begin{aligned} & \mathrm{R}^{2}=0,97 \\
& \mathrm{R}^{2}=0,97 \\
& \mathrm{R}^{2}=0,97 \\
& \mathrm{R}^{2}=0,96 \\
& \text { EMAn }_{4}{ }^{2}\end{aligned}$} \\
\hline $\begin{array}{l}\text { Alimento } \\
\text { Feedstuff }\end{array}$ & EMAn $^{1}$ & EMAn $_{1}^{2}$ & $\mathrm{EMAn}_{2}{ }^{2}$ & $\mathrm{EMAn}_{3}^{2}$ & \\
\hline $\begin{array}{l}\text { Milho } 1 \\
\text { Corn } 1\end{array}$ & 3699 & 3555 & 3661 & 3564 & 3562 \\
\hline $\begin{array}{l}\text { Milho } 2 \\
\text { Corn } 2\end{array}$ & 3529 & 3550 & 3772 & 3604 & 3668 \\
\hline $\begin{array}{l}\text { Milho QPM } \\
\text { Quality protein maize }\end{array}$ & 3647 & 3641 & 3650 & 3637 & 3650 \\
\hline $\begin{array}{l}\text { Milho pré-cozido } \\
\text { Pre-cooked corn }\end{array}$ & 3728 & 3786 & 3702 & 3758 & 3770 \\
\hline $\begin{array}{l}\text { Farelo de glúten } 60 \\
\text { Corn gluten feed }\end{array}$ & 4108 & 4113 & 4116 & 4152 & 4043 \\
\hline $\begin{array}{l}\text { Farelo de glúten } 21 \\
\text { Corn gluten meal }\end{array}$ & 1937 & 1935 & 1913 & 1935 & 1863 \\
\hline $\begin{array}{l}\text { Gérmen de milho (GM) } \\
\text { Corn germ }(C G)\end{array}$ & 3272 & 3409 & 3469 & 3382 & 3378 \\
\hline $\begin{array}{l}\text { Gérmen de milho fino } \\
\text { Fine corn germ }\end{array}$ & 3588 & 3517 & 3500 & 3445 & 3465 \\
\hline $\begin{array}{l}\text { GM desengordurado } \\
\text { Free-fat } C G\end{array}$ & 2448 & 2449 & 2475 & 2480 & 2558 \\
\hline $\begin{array}{l}\text { Médias } \\
\text { Means }\end{array}$ & 3328 & 3328 & 3329 & 3329 & 3329 \\
\hline $\begin{array}{l}\text { Médias da soma do } \\
\text { quadrado dos desvios } \\
\text { Deviation square sum me }\end{array}$ & & 5364 & 5917 & 6696 & 9791 \\
\hline
\end{tabular}

1 Energia metabolizável aparente corrigida, observada "in vivo" no ensaio com pintos em crescimento.

2 Estimativas da EMAn pelas equações de predição.

1 Aparent corrected metabolizable energy, "in vivo" observed in the growing chickens assay.

2 AMEn estimates by the prediction equations. 
Tabela 7 - Estimativas dos valores de EMVn do milho e subprodutos, determinados com galos adultos, por meio de equações de predição dos valores energéticos, em função da composição dos alimentos ( $\mathrm{kcal} / \mathrm{kg}$ de matéria seca)

Table 7 - Estimate of the TMEn values of corn and byproducts, determined with chickens, by the prediction equations of the energetic values based on the food composition ( $\mathrm{kcal} / \mathrm{kg}$ of the dry matter)

$\mathrm{EMVn}_{1}=4187,17-59,69 \mathrm{~PB}+203,81 \mathrm{FDA}-54,71 \mathrm{FDN}+117,61 \mathrm{EE}-107,70 \mathrm{MM}$

$\mathrm{EMVn}_{2}=5283,87-10,46 \mathrm{~PB}-127,51 \mathrm{FB}+27,62 \mathrm{EE}-171,63 \mathrm{MM}-14,07 \mathrm{AMIDO}$

$\mathrm{R}^{2}=0,99$

$\mathrm{EMVn}_{3}=4234,28-27,58 \mathrm{FDN}+50,18 \mathrm{EE}-107,54 \mathrm{MM}$

$\mathrm{R}^{2}=0,99$

$\mathrm{EMVn}_{4}=4485,13-34,20 \mathrm{FDN}-83,83 \mathrm{MM}$

\begin{tabular}{|c|c|c|c|c|c|}
\hline $\begin{array}{l}\text { Alimento } \\
\text { Feedstuffs }\end{array}$ & $\mathrm{EMVn}^{1}$ & $\mathrm{EMVn}_{1}^{2}$ & $\mathrm{EMVn}_{2}^{2}$ & $\mathrm{EMVn}_{3}^{2}$ & $\mathrm{EMVn}_{4}{ }^{2}$ \\
\hline Milho 1 & 4015 & 3969 & 3880 & 3788 & 3848 \\
\hline $\begin{array}{l}\text { Corn 1 } \\
\text { Milho } 2\end{array}$ & 3701 & 3682 & 3724 & 3875 & 3931 \\
\hline $\begin{array}{l}\text { Corn } 2 \\
\text { Milho QPM } \\
\text { Quality protein maize }\end{array}$ & 3903 & 3922 & 3934 & 3954 & 3922 \\
\hline $\begin{array}{l}\text { Milho pré-cozido } \\
\text { Pre-cooked corn }\end{array}$ & 3856 & 3863 & 3915 & 3915 & 4025 \\
\hline $\begin{array}{l}\text { Farelo de glúten } 60 \\
\text { Corn gluten meal }\end{array}$ & 4248 & 4254 & 4255 & 4214 & 4252 \\
\hline $\begin{array}{l}\text { Farelo de glúten } 21 \\
\text { Corn gluten feed }\end{array}$ & 2246 & 2231 & 2234 & 2275 & 2237 \\
\hline $\begin{array}{l}\text { Gérmen de milho(GM) } \\
\text { Corn germ - CG }\end{array}$ & 3782 & 3850 & 3822 & 3801 & 3662 \\
\hline $\begin{array}{l}\text { Gérmen de milho fino } \\
\text { Fine corn germ }\end{array}$ & 3962 & 3920 & 3929 & 3920 & 3709 \\
\hline $\begin{array}{l}\text { GM desengordurado } \\
\text { Free-fat } C G\end{array}$ & 2727 & 2751 & 2745 & 2699 & 2854 \\
\hline $\begin{array}{l}\text { Médias } \\
\text { Means } \\
\text { Médias da soma do qu } \\
\text { dos desvios } \\
\text { Deviation square sum me }\end{array}$ & 3605 & 3605 & 3604 & 3604 & 3604 \\
\hline
\end{tabular}

\footnotetext{
$\overline{1}$ Energia metabolizável aparente corrigida, observada in vivo no ensaio com pintos em crescimento (Aparent corrected metabolizable energy, in vivo observed in the assay with growing chickens).

2 Estimativas da EMAn pelas equações de predição (AMEn estimates by the prediction equations).
}

\section{Conclusões}

Os valores energéticos das amostras de milho 1 , 2, QPM e pré-cozido, farelos de glúten 60 e 21, gérmen de milho, gérmen de milho fino, gérmen de milho desengordurado e milhetos 1 e 2 foram 3699 e $4015 ; 3529$ e 3701; 3647 e 3903; 3728 e 3856; 4108 e 4248 ; 1937 e $2246 ; 3272$ e $3782 ; 3588$ e $3962 ; 2448$ e $2729 ; 3248$ e $3719 ; 3347$ e $3804 \mathrm{kcal} / \mathrm{kg}$ de MS, respectivamente, para as EMAn determinadas com pintos e EMVn com galos adultos; o milheto poderá constituir em um alimento alternativo ao milho, com valores energéticos pouco inferiores; as equações ajustadas com duas a quatro variáveis fazem boas predições dos valores energéticos dos alimentos do grupo do milho, com valores de $\mathrm{R}^{2}$ superiores a 91\%; as equações contendo a FDN e MM ou FB e MM são boas preditoras dos valores de EMAn obtidos com pintos e EMVn com galos, para o milho e seus subprodutos, sendo: $\mathrm{EMAn}=4281,6$ - 39,97FDN $72,90 \mathrm{MM}\left(\mathrm{R}^{2}=0,96\right)$ ou $4354,8-112,05 \mathrm{FB}-151,74 \mathrm{MM}$
$\left(\mathrm{R}^{2}=0,95\right)$ e $\mathrm{EMVn}=4485,1-34,20 \mathrm{FDN}-83,83 \mathrm{MM}$

$\left(\mathrm{R}^{2}=0,94\right)$ ou $4250,2-136,60 \mathrm{FB}-120,48 \mathrm{MM}\left(\mathrm{R}^{2}=0,91\right)$.

\section{Referências Bibliográficas}

ADEOLA, O., ROGLER, J.C. 1994. Pearl millet in diets of white pekin ducks. Poult. Sci., 73(2):425-435.

ALBINO, L.F.T. Sistemas de avaliação nutricional de alimentos e suas aplicações na formulação de rações para frangos de corte. Viçosa, MG: UFV, 1991. 141p. Tese (Doutorado em Zootecnia) - Universidade Federal de Viçosa, 1991.

ALBINO, L.F.T., SILVA, M.A. Valores nutritivos de alimentos para aves e suínos determinados no Brasil. In: SIMPÓSIO INTERNACIONAL SOBRE EXIGÊNCIAS NUTRICIONAIS DE AVESE SUÍNOS, 1996, Viçosa. Anais... Viçosa: UFV, 1996. p.303-318.

ALBINO, L.T.F., ROSTAGNO, H.S., TAFURI, M.L. et al. 1992a. Determinação dos valores de energia metabolizável aparente e verdadeira de alguns alimentos para aves, usando diferentes métodos. R. Soc. Bras. Zootec., 21(6):1047-1058.

ALBINO, L.F.T., COELHO, M.G.R., RUTZ, F. et al. 1987.Valores energéticos e de triptofano de alguns alimentos determinados, em aves jovens e adultas. Pesq. Agropec. Bras, 22(11/12):1301-1306.

ALBINO, L.F.T., FIALHO, E.T., BRUM, P.A.R. et al. 1992b. Determinação dos valores energéticos de alguns alimentos 
para aves. In: REUNIÃO ANUAL DA SOCIEDADE BRASILEIRA DEZOOTECNIA, 29, 1992, Lavras. Anais... Lavras: SBZ, 1992. p.330.

ALBINO, L.F.T., RUTZ, F., BRUM, P.A.R. et al. 1989. Energia metabolizável aparente e verdadeira de alguns alimentos determinados com galos. Pesq. Agropec. Bras., 24(12):1433-1437.

AMERLIN, M.J.A., VIEIRA-BRESSAN, M.C.R., BENATTI, A.B. et al. 1998. Multielement determination in cattle hair infested with boophilus microplus by instrumental neutron activation analysis. J. Radioanalytical and Nuclear Chemistry, 236(1-2):77-79.

ANFAL - ASSOCIAÇÃO NACIONAL DOS FABRICANTES DE ALIMENTOS PARA ANIMAIS. Perfil 2000: Indústria brasileira de alimentação animal. Encarte de: Alimentação Animal. São Paulo, v.5, n.17, jan/mar 2000 .

AZEVEDO, D.M.S. Fatores que afetam os valores de energia metabolizável da farinha de carne e ossos para aves. Viçosa, MG: UFV, 1996. 68p. Dissertação (Mestrado em Zootecnia) - Universidade Federal de Viçosa, 1996.

BAIDOO, S.K.; SHIRES, A.; ROBBLEE, A.R. 1991.Effect of Kernel density on the apparent and true metabolizable energy value of corn for chickens. Poult. Sci., 32(10):2102-2107.

BATH, D., DUNBAR, J., KING, J. et al. 1999. Byproducts and unusual feedstuffs. Feedstuffs, 71(31).

BORGES, F.M.O., ROSTAGNO, H.S., BAIÃO, N.C. et al. Avaliação de métodos para estimar energia metabolizável em alimentos para aves. In: REUNIÃO ANUAL DA SOCIEDADE BRASILEIRA DE ZOOTECNIA, 35, Botucatu, SP, 1998. Anais... Botucatu: SBZ, 1998a. p.386-388.

BORGES, F.M.O., ROSTAGNO, H.S., RODRIGUEZ, N.M. et al. Metodologia de alimentação forçada em aves. 1 - Efeito dos níveis de consumo de alimento na avaliação da energia metabolizável. In: REUNIÃO ANUAL DA SOCIEDADE BRASILEIRA DE ZOOTECNIA, Botucatu, SP, 1998. Anais... Botucatu: SBZ, 1998b. p.389-391.

BRASIL. MINISTÉRIO DA AGRICULTURA e ABASTECIMENTO - MAARA; SINDICATO NACIONAL DA INDÚSTRIA DE ALIMENTAÇÃO ANIMAL - SINDIRAÇÕES; ASSOCIAÇÃO NACIONAL DOS FABRICANTES DE RAÇÕES ANFAR; COLÉGIO BRASILEIRO DE NUTRIÇÃO ANIMAL - CBNA. Compêndio Brasileiro de Alimentação Animal - São Paulo: ANFAR. 1998. p.irr. Matérias primas; padronização de matéria prima para alimentação animal, 1998. p.1-51.

CAFÉ, M.B., STRINGHINI, J.H., MOGYCA, N.S. et al. Avaliação nutricional do milheto(Penissetum americanum) para alimentação de aves. In: CONFERENCIA APINCO DE CIÊNCIA E TECNOLOGIA AVÍCOLAS, Porto Alegre, RS, 1999. Anais... Curitiba: FACTA, 1996. p.40.

COLLINS, V.P., CANTOR, A.H., PESCATORE, A.J. et al. 1997. Pearl millet in layer diets enhances egg yolk n-3 fatty acids. Poult. Sci., 76(2):326-330.

DALE, N. Ingredient analysis table: 1999 edition. 1999. Feedstuffs, 71(31):24-31.

DALE, N., FULLER, H. L. 1984. Correlation of protein content of feedstuffs with the magnitude of nitrogen correction in true metabolizable energy determination. Poult. Sci., 63(5):1008-1012.

DOLZ, S., DEBLAS, C. 1992. Metabolizable energy of meat and bone meal from Spanish rendering plants as influenced by level of substitution and method of determination. Poult. Sci., 71(2):316-322.

EMBRAPA-CNPSA. 1991. Tabela de composição química evalores energéticos de alimentos para suínos e aves. 3.ed. Concórdia: CNPSA. 97p. (Documentos, n.19).

UNIVERSIDADE FEDERAL DE VIÇOSA - UFV. 1992. SAEG Sistema de análises estatísticas e genéticas. Versão 5.0. Viçosa, MG: 59p. (Manual do usuário).

FISCHER JR., A.A., ALBINO, L.F.T., ROSTAGNO, H.S. etal. 1998. Determinação dos valores de energia metabolizável de alguns alimentos usados na alimentação de aves. R. Soc. Bras. Zootec., 27(2):314-318.

Rev. bras. zootec., 30(6):1767-1778, 2001
JANSSEN, W.M.M.A. European table of energy values for poultryfeedstuffs. 3.ed. Beekbergen, 1989.84p. (Spelderholt Center for Poultry Research and Information Services).

LECLERCQ, B., HENRY, Y., PEREZ, J.M. Valor energético dos alimentos destinados aos animais monogástricos In: INSTITUT NATIONAL DE LA RECHERCHE AGRONOMIQUE - INRA. Alimentação dos animais monogástricos; suínos, coelhos e aves. Tradução de Paulo Marcos Agria de Oliveira. 2.ed. São Paulo: Roca, 1999. Cap.2, p. 9-15. Tradução de L'alimentation des animaux monogastriques.

LESSON, S., SUMMERS, J.D. 1997. Commercial poultry nutrition. 2.ed. Guelph, Ontário: University Books. 350p.

LESSON, S., YERSIN, A., VOLKER, L. 1993. Nutritive value of the 1992 corn grop. J. Applied Poult. Res., 2:208-213.

LIMA, I.L., SILVA, D.J., ROSTAGNO, H.S. et al. 1989. Composição química e valores energéticos de alguns alimentos determinados com pintos e galos, utilizando duas metodologias. R. Soc. Bras. Zootec., 18(6):546-556.

MATTERSON, L.D., POTTER, L.M., STUTZ, M.W. et al. 1965. The metabolizable energy offeed ingredients for chickens. Storrs, Connecticut, The University of Connecticut, Agricultural Experiment Station, 11p.(Research Report, 7).

NASCIMENTO, A.H., GOMES, P.C., ALBINO, L.F.T. et al. 1998. Valores de composição química e energética de alimentos para frangos de corte. R. Soc. Bras. Zootec., 27(3):579-583.

NATIONALRESEARCHCOUNCIL-NRC.1994.Nutrientrequirements of poultry. 9 ed. Washington: National Academy Press. 155p.

NELSON, N.A. 1944. A photometric adaptation of Somogy method for the determination of glucose. Journal of Biological Chemistry, Baltimore, 153:375-380.

NUNES, R.V. Valores energéticos e de aminoácidos digestiveis da grão de trigo e seus subprodutos para aves. Viçosa, MG: UFV, 1999. 71p. Dissertação (Mestrado em Zootecnia) Universidade Federal de Viçosa.

RAGLAND, D., KING, D; ADEOLA, O. 1997. Determination of metabolizable energy contents of feed ingredients for ducks. Poult. Sci., 76(9):1287-1291.

ROSTAGNO, H.S., SILVA, D.J., COSTA, P.M.A. et al. 1983. Composição de alimentos e exigências nutricionais de aves e suínos (tabelas brasileiras). Viçosa: UFV. 59p.

ROSTAGNO, H.S., SILVA, M.A. Disponibilidade de nutrientes em grãos de má qualidade. In: SEMINARIO INTERNACIONAL EN CIENCIAS AVICOLAS - CONFERENCIAS EMPRESARIALES EXPO AVICOLA'97. Santa Cruz, 1997. Anais... Santa Cruz: AMEVEA, 1997. p.155-166.

SIBBALD, I.R. 1976. A bioassay for true metabolizable energy in feedingstuffs. Poult. Sci., 55(1):303-308.

SIBBALD, I.R.,PRICE, K., BARRETTE, J.P. 1980. True metabolizable energy values for poultry of commercial diets measured by biossay and predicted from chemical data. Poult. Sci., 59(4):808-811.

SILVA, D.J. 1990. Análise de alimentos (métodos químicos e biológicos). 2.ed. Viçosa: UFV. 165p.

WOLYNETZ, M.N., SIBBALD, I.R. 1984. Relationships between apparent na true metabolizable energy and the effects of a nitrogen correction. Poult. Sci., 63(7):1386-1399.

ZANOTTO, D.L., MONTICELLI, C.J. Granulometria do milho em rações para suínos e aves: digestibilidade de nutrientes e desempenho animal. In: SIMPÓSIO SOBRE GRANULOMETRIA DE INGREDIENTES E RAÇÕES PARA SUÍNOS E AVES, Concórdia, SC, 1998. Anais... Concórdia: EMBRAPA, 1998. p.26-47.

Recebido em: 21/02/01 Aceito em: 27/07/01 